\title{
Limites e fronteiras das políticas assistenciais entre os séculos XVI e XVIII
}

\author{
continuidades e alteridades*
}

\section{Limits and frontiers of the poor relief and health care policies between the $16^{\text {th }}$ and $18^{\text {th }}$ centuries continuities and alterities}

LAURINDA ABREU

Departamento de História da Universidade de Évora Colégio do Espírito Santo, Gabinete 243, Apartado 94 7002-554 Évora Ifsa@uevora.pt

RESUMO A partir dos conceitos de ação coletiva e de atores com interesses e do pressuposto de que o campo da caridade, assistência e saúde foi politicamente definido desde o início do período moderno, este texto tem dois objetivos principais: por um lado, analisar a construção do sistema assistencial português, identificando as suas linhas de continuidade durante todo o Antigo Regime. Por outro, avaliar as razões da maior eficácia da Coroa de quinhentos quando comparada com os governos da segunda metade de Setecentos, em termos de reforma das estruturas de apoio social e implementação de um novo paradigma assistencial. Em ambos os casos obviamente tendo em conta as diferenças entre os contextos políticos e sociais dos dois momentos em análise.

* Artigo recebido em: 24/06/2010. Aprovado em: 4/08/2010. 
Palavras-chave políticas assistenciais, período moderno, intervenção política

ABSTRACT Using the concepts of the collective action and actors with interests and the assumption that the poor relief and health care field was politically defined since the early modern period, this paper has two main purposes: on the one hand, to analyze the construction of the Portuguese assistance system, identifying its lines of continuity during the Ancient Regime. On the other hand, to evaluate the reasons why the Crown of the $16^{\text {th }}$ century was more efficient when compared with the governments of the second half of the $18^{\text {th }}$ century, in terms of reform of the social structures and implementation of a new paradigm of assistance. In both cases, taking into account the differences between the political and social contexts of those two moments.

Keywords poor relief and health care policies, early modern period, political intervention

\section{Introdução}

Na viragem do século XV para o XVI, em Portugal como em vários outros espaços europeus, assistiu-se a uma mudança na forma de pensar e praticar a caridade e, de um modo geral, as questões de saúde e do bem-estar das populações. Tratou-se de movimento gradual, em boa parte determinado pelo impacto das transformações económicas e sociais, mas também pelos novos modelos culturais, que foram sendo registados, em diferentes ângulos e perspectivas, nos textos teológicos, no vocabulário jurídico e nos discursos normativos. Verdadeiros quadros de referência para a nova ordem social que se pretendia promover, é nestes últimos que mais facilmente se colhem as modernas ideias que começavam a reconfigurar a medieval imagem do pobre merecedor, redefinindo os parâmetros da elegibilidade para aceder aos recursos assistenciais ${ }^{1}$ e separando as necessidades dos doentes das dos pobres, ${ }^{2}$ ainda que mantendo a proximidade entre ambos.

Desde a renovação historiográfica operada nos anos 80 do século passado que a maioria dos investigadores das questões sociais se recusa

1 Uma elucidativa síntese do processo inglês, que abre pistas de análise para o português, pode encontrar-se em HINDLE, Steve. On the Paris? The micro-politics of poor relief in rural England c.1550-1750. Oxford: Clarendon Press, 2009, p.1-3. Isto sem ignorar, obviamente, as diferenças que separam os dois sistemas, nomeadamente em relação às principais formas de financiamento (caridade em Portugal, impostos em Inglaterra) e implantação legal (enquanto a Inglaterra desenvolveu seu sistema a partir da intervenção legislativa do Parlamento, em Portugal o processo foi negociado pela corte e a legislação versou sobretudo as Misericórdias).

2 Refere-o de uma forma clara D. Manuel I na carta que em 23 de maio de 1502 enviou à Câmara de Évora proibindo-a de acolher no Hospital do Espírito Santo os "proues saãos que bem podem trabalhar", porque o hospital se destinava aos doentes. Évora. Arquivo Distrital de Évora. (ADE) Livro I dos Originais, n. 71, fl.251. 
aceitar as perspectivas redutoras usadas pelo século XIX para definir os conceitos de saúde pública e de população ${ }^{3}$ bem como as perspectivas de análise que reduzem a intervenção das autoridades primomodernas a meras obrigações morais e religiosas. Em alternativa, alguns deles propõem-se incluir no debate a dimensão política e institucional da ação dos poderes dominantes enquanto organizadores desse campo social. E não apenas no sentido civilizador identificado por Norbert Elias, ${ }^{4}$ mas enquanto elemento propiciador de criação de poder social coletivo, que contribuiu para a estruturação do próprio Estado. Formulações que, obviamente, defendem que o Estado pode ser abordado em outras dimensões e princípios ${ }^{5}$ que não exclusivamente os weberianos, ${ }^{6}$ que o reduzem a um fenómeno institucional. ${ }^{7}$ Ao introduzir outras variáveis na problemática da construção do Estado Moderno, essa nova abordagem alarga o campo de pesquisa, sem negligenciar os usuais fatores de análise: as proposições doutrinais, de índole religiosa ou jurídica, os contextos socioeconómicos e a cultura política vigente.

O que se constata no caso português é que a Coroa quinhentista, apesar de suas múltiplas e conhecidas limitações, foi capaz de impor regras a todo o país e organizar, sob pressupostos orgânicos comuns, as tradicionais formas de provimento e distribuição dos recursos caritativos. É certo que a parcimónia de estudos monográficos nessa área não permite aferir de eventuais especificidades locais e regionais nem da dimensão dos contrastes entre as comunidades urbanas e as rurais, impedindo, assim, a enunciação de conclusões definitivas. Mas a impressiva semelhança de práticas e procedimentos implementados pelas quase quatro centenas de misericórdias fundadas em território português no período moderno ${ }^{8}$ revela enorme eficiência do poder central na transmissão da informação, mostrando-o capaz de comunicar até às periferias os seus modelos assistenciais que, se não eram de formatação social, ${ }^{9}$ pelo menos conformavam as populações aos valores e objetivos da monarquia. E não foram apenas

3 Cf. PORTER, Dorothy. (ed.) The history of health and the Modern State. Amsterdam/Atlanta: Rodopi, 1994. Uma análise a esta problemática pode encontrar-se no seguinte trabalho: PORTER, Dorothy. The History of Public Health: Current Themes and Approaches. Hygiea Internationalis, v.1, p.9-21, 1999.

4 Cf. ELIAS, Norbert. The civilising process. London, 1994, p.335-421. (1ª edição 1939)

5 Na perspectiva em que Michael Braddick o formulou em seu texto. Cf. BRADDICK, M. State formation and social change in Early Modern England: a problem stated and approaches suggested. Social History, v.16, n.1, p.1-17, jan. 1991.

6 Aqui assumidas como Michael Mann as sintetizou: "the state is a centralized, differentiated set of institutions enjoying a monopoly of the means of legitimate violence over a territorially demarcated area". Cf. MANN, Michael. State and society, 1130-1815: An analysis of English state finances. In: ZEITLIN, M. (ed.) Political power and social theory. Greenwich/Connecticut: JAI Press, 1979, v.l, 1980, p.165-208.

7 Como temos vindo a propor para Portugal e desenvolvemos em Assistance et santè publique dans la construction de l'État Moderne: l'expérience portugaise. (no prelo).

8 Conforme demonstrado nos diferentes volumes da obra Portugaliae Monumenta Misericordiarum. Lisboa: Universidade Católica/União das Misericórdias Portuguesas, 2002-2009.

9 Sobre essas questões, veja-se PARKER, Charles $\mathrm{H}$. The reformation of community. Social welfare and Calvinist charity in Holland, 1572-1620. Cambridge: Cambridge Press, 1998, p.1-19. 
as misericórdias a entrar nessa causa. Ainda que de menor dimensão em termos de visibilidade social, antes das misericórdias já a Coroa tinha iniciado a reforma dos hospitais e, depois das misericórdias e dos hospitais, sem nunca os abandonar, haveria de estender sua ação até ao campo sanitário, impondo, entre outras diretrizes, a formação académica de profissionais de saúde à custa do financiamento municipal. No seu conjunto, todas essas operações acabariam por internalizar valores e regular a vida social. Aplicando a essa situação a grelha analítica proposta por Michael Braddick, pode concluir-se que no século XVI a Coroa portuguesa conseguiu criar um alargado consenso normativo na área da caridade e da assistência, e, como assumiu a coordenação do processo, recolheu daí os respectivos dividendos. $\mathrm{E}$ isso sem recorrer ao frágil aparelho administrativo nem usar seus recursos financeiros.

É por esse conjunto de razões - que em muito ultrapassam as preocupações com a saúde pública que, desde a obra de George Rosen, de 1958, foram reconhecidas ao Estado mercantilista ${ }^{10}$ - que tenho colocado as questões assistenciais no âmbito das ações políticas conducentes à emergência do Estado Moderno. E é nessa mesma linha interpretativa que entendo as dificuldades que o Estado setecentista experimentou quando procurou substituir o modelo herdado do século XVI por outro, mais conforme "às Luzes do século". Evidentemente que semelhante afirmação deve ser relativizada em função dos diferentes contextos políticos, sociais e culturais. Com certeza que entre aqueles dois momentos se registaram alterações na forma de encarar os fenómenos sociais e no modo de os resolver. $O$ enquadramento político do século XVIII não era, a não ser marginalmente, tocado por concepções teológicas, como tinha sido o do século XVI. Por outro lado, a ruptura de paradigmas governativos iniciada por Sebastião José de Carvalho e Melo, futuro marquês de Pombal, e a imposição de novos modelos políticos que encaravam as questões sociais sob o utilitarista princípio do "interesse público", haveriam de sustentar formas de intervenção social estranhas ao Portugal de Quinhentos. ${ }^{11}$ Mas reconhecer que no século XVIII houve mudanças importantes não implica subestimar o trabalho antes realizado, a similitude dos propósitos perseguidos e, acima de tudo, a forma como o passado se projetou nas reformas pretendidas. Nos finais do século XVIII, quando o intendente-geral da Polícia, Diogo Inácio de Pina Manique, ${ }^{12}$ desenvolveu seu programa social seguindo o exemplo mer-

10 Cf. ROSEN, George. History of public health. New York: MD Publications, 1958. Trata-se, como bem se sabe, de obra de carácter heróico e teleológico, mas que foi precursora das novas abordagens historiográficas às práticas e políticas de saúde modernas e contemporâneas.

11 A propósito dessas questões, vejam-se as estimulantes interpretações de SUBTIL, José. O terramoto político (1755-1759). Memória e poder. Lisboa: UAL, 2007.

12 Diogo Inácio de Pina Manique (1733-1805) desempenhou vários cargos na administração pública ao tempo do Marquês de Pombal, mas foi como intendente-geral da Polícia (1780-1803), já no reinado de dona Maria I, que mais se destacou. Figura controversa do final do Antigo Regime em Portugal, o desconhecimento que ainda paira 
cantilista prussiano da medical police e não o do humanitarismo iluminista de pendor filantrópico e cívico, que estava a ser defendido por D. Rodrigo de Sousa Coutinho, ${ }^{13}$ fê-lo na continuidade dos modelos de intervenção social pombalinos porque as circunstâncias políticas e económicas assim o determinavam, mas também porque era o que mais se aproximava do processo histórico português. O que queremos afirmar é que, em relação à assistência e à saúde, nem as opções legislativas de Sebastião José de Carvalho e Melo nem a atuação prática de Pina Manique, apesar de fortemente interventoras, significaram ruptura abrupta com o passado. Por outro lado, embora fossem outras as circunstâncias e as competências do Estado, nenhum deles se aproximou do nível de eficiência dos monarcas de quinhentos, se a tomarmos como capacidade para construir um modelo de raiz, que sobreviveu, apesar das adaptações, aos políticos do século XVIII, projetando-se na centúria seguinte.

A intenção deste texto não é a de estabelecer comparações entre dois períodos tão distintos nem sequer entrar na discussão sobre a emergência do Estado moderno mas, tão somente, analisar as questões assistenciais no Portugal moderno por um prisma mais político-social. E, nessa perspectiva, procurar explicar as linhas de continuidade nas políticas de assistência formal e as razões da maior eficácia da Coroa do século XVI quando comparada com a da segunda metade do século XVII - tendo em conta, naturalmente, a diversidade e complexidade reconhecida a cada época e as diferentes percepções sociais e políticas que lhes estiveram associadas.

\section{Os conceitos e as premissas de análise}

Este trabalho, que cronologicamente se centra em dois momentos precisos, o século XVI e a segunda metade do século XVIII, desenvolve-se a partir de ideias já enunciadas: a premissa de que as problemáticas da assistência e da saúde pública estão vinculadas às dinâmicas do poder - independentemente da natureza do centro irradiador desse poder, ${ }^{14}$ devendo, portanto, ser enquadradas enquanto ações políticas; e os conceitos

sobre várias das múltiplas vertentes em que atuou faz com que seja mais conhecida a perseguição implacável que moveu ao ideário político e social que esteve na base da Revolução Francesa, e a seus difusores, do que sua, não menos revolucionária, intervenção no campo sanitário e da saúde pública.

13 "Homem de Estado de grande cultura, e figura marcante da governação post-pombalina", assim o apresenta SILVA, Andrée Mansuy Diniz. D. Rodrigo de Souza Coutinho, textos políticos, económicos e financeiros. 17831811, Lisboa: Banco de Portugal, 1993. D. Rodrigo de Souza Coutinho, Conde de Linhares, desempenhou os cargos de ministro e secretário de Estado da Marinha e Domínios Ultramarinos (1796-1801), presidente do Real Erário e ministro e secretário de Estado da Fazenda (1801-1803), e ministro da Guerra e Negócios Estrangeiros (1808-1812), este último já no Brasil, para onde se deslocara na companhia da Corte em 1807. Sobre as propostas assistenciais do Conde de Linhares, veja-se ABREU, Laurinda. Um sistema antigo num regime novo: permanências e mudanças nas políticas de assistência e saúde (1780-1840). O caso do Alentejo. In: Actas do 1o Colóquio de História do Alentejo, O Alentejo entre o Antigo Regime e a Regeneração. Mudanças e permanências. (no prelo).

14 No sentido tomado da obra editada por Jonathan Barry e Colin Jones, em que se valorizam as múltiplas entidades "fornecedoras" de recursos de bem-estar, independentemente do tipo de poder político dominante, isto é, mais ou menos centralizado. Cf. BARRY, J. e JONES, C. Medicine, charity and the Welfare State. London, 1991. 
organizadores de ação coletiva e de atores com interesses, na formulação que lhes foi dada por Dorothy Porter e Marco Van Leeuwen, respectivamente. Sob essa lógica analítica, assumimos que o campo foi politicamente definido e que a execução das orientações das autoridades só se tornou possível porque o poder político conseguiu envolver os diferentes grupos sociais, disponibilizando-Ihes um conjunto de benefícios que tornaram atrativa sua participação.

A mobilização coletiva, subentendida na frase anterior, não significa, contudo, que todos os atores tivessem interesses iguais. Muito pelo contrário. Todavia, ao interagirem, os intervenientes desenhavam um espaço comum em que se definiam os diferentes papéis e recursos disponíveis, uns e outros reconhecidos pelo grupo. Como Van Leeuwen sintetizou, do lado das elites as motivações eram múltiplas: do foro religioso e moral as primeiras que a historiografia identifica -, mas muito mais para além delas: entre suas preocupações estavam a estabilização da ordem social e pública, as necessidades do mercado de trabalho, o receio do contágio epidémico e, naturalmente, o capital social associado às práticas caritativas, que Ihes granjeava oportunidades políticas, patronato sobre importantes instituições, facilidades financeiras, aumento de autoridade ou sua legitimação. Tratava-se, em síntese, de uma forma específica de investimento com retorno garantido.

O que os mais recentes estudos vêm demonstrando é que os pobres, pelo menos alguns deles, não eram meros receptores passivos da generosidade dos mais afortunados, remetidos ao papel de vítimas das autoridades que se serviriam da caridade como forma de disciplina social, às vezes de modo subtil, outras pedagogicamente agressivas, como teriam sido as políticas de renfermement. ${ }^{15}$ Supostamente dominantes na Europa dos séculos XVIII e XIX, de acordo com as interpretações tributárias das perspectivas teóricas veiculadas pelos estudos iniciais de Foucault, ${ }^{16}$ essas interpretações, que nunca foram de aceitação geral, têm vindo a ser substituídas por análises que preferem considerar que os sistemas sociais modernos foram construídos por "atores com interesses"17 e cimentados pelas dinâmicas e interdependências que os ligavam uns aos outros. Uma visão que tem em conta dois fenómenos a que a escola de Foucault não prestou particular atenção: a importância das multivariadas formas de

15 Alguns estudos sobre essas questões são referenciados por JONES, Colin. Some recent trend in the history of charity. In: DAUTON, Martin. (ed.) Charity, self-interest and welfare in the English past. London/New York: Routledge, 1996, p.51-63.

16 Particularmente em: FOUCAULT, M. Histoire de la folie à l'âge classique. Folie et déraison. Paris: Plon, 1961; FOUCAULT, M. Surveiller et punir. Paris: Gallimard, 1975.

17 Na eficiente explicação de VAN LEEUWEN, M. H. D. Logic of charity: poor relief in Preindustrial Europe. Journal of Interdisciplinary History, v.24, n.4, Spring, p.589-613, 1994. Análise que o autor desenvolve a partir de alguns trabalhos, nomeadamente BOUDON, R. The logic of social action. London: Routledge, 1981. 
assistência domiciliária, pouco estudadas ${ }^{18}$ e, portanto, subavaliadas, e o papel que os grandes hospitais, apontados como os centros dessas mesmas políticas de clausura, desempenharam enquanto espaços de apoio às comunidades. ${ }^{19}$

Como a investigação em curso para Évora demonstra (para os séculos

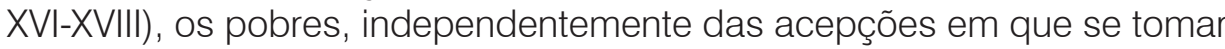
o vocábulo, eram, de facto, capazes de construir suas próprias redes de auxílio mútuo, ainda que sua densidade dependesse do capital social que possuíam, ${ }^{20}$ e de utilizar diferentes expedientes para aceder aos recursos que a assistência formal disponibilizava, várias vezes interferindo nos processos e mesmo manipulando-os. Por exemplo, omitindo rendimentos quando solicitavam apoio à Misericórdia ou ao Cabido (rendas que conseguimos recuperar nos Livros de Décimas), sonegando a uma entidade a informação de que estavam a ser apoiados pela outra, circulando entre as diferentes instituições assistenciais conforme as circunstâncias da vida. Igualmente bem documentado, em Évora como em muitas outras cidades, europeias e não só, era o abandono de crianças por mães que, logo após a exposição, se ofereciam como amas na esperança de criarem seus filhos a expensas das entidades que tinham semelhante encargo, recebendo ainda um salário por seu trabalho. E se são poucas as hipóteses de relacionar esse fenómeno específico com o agravamento das situações económicas, são vários os estudos que desvendam uma correlação positiva entre a exposição e as conjunturas de crise aparecendo aquela como consciente estratégia de captação de recursos por parte das famílias pobres, que visava também, eventualmente, aumentar as hipóteses de sobrevivência das crianças. Mas nunca a encontrámos tão claramente expressa como no ofício que Pina Manique, como intendente-geral da Polícia, dirigiu ao juiz de fora de Belmonte, em 17 de abril de 1791, autorizando a entrega dos expostos da vila de Sortelha às respectivas mães, desde que confirmada a filiação: a situação de pobreza levara as mulheres casadas a abandonar seus filhos na Roda, mas, como nem a vila nem os lugares vizinhos conseguiam pagar o imposto extraordinário (fintas) destinado aos enjeitados, as mães tinham quebrado o sigilo do abandono e procuravam recuperar os filhos, resgatando-os da morte. ${ }^{21}$

18 Temática que está a ser estudada para Évora, em PARDAL, Rute. Práticas de caridade, assistência e contro/o social, em Évora, no período moderno. (Tese de doutoramento).

19 Cf. HORDEN, Peregrine. Household care and informal networks. Comparisons and continuities from antiquity to the present. In: HORDEN, Peregrine and SMITH, Richard. (eds.) The locus of care. Families, communities, institutions and the provision of welfare since antiquity. London/New York: Routledge, 1998, p.21-25.

20 Para uma genealogia do conceito cunhado por R. Putnam e suas diferentes aplicações, veja-se SZRETER, Simon. The state of social capital: bringing back in power, politics, and history. Theory and Society, v.31, n.5, p.573-621, October 2002. Um estudo a fazer para Portugal é o que analise as redes locais dos pobres e os mecanismos de autoajuda como forma de investimento a capitalizar em caso de necessidade.

21 Lisboa. Academia das Ciências de Lisboa. (ACL) Série Vermelha, v.l, n.21, fol.16. 
O êxito desses grupos de pobres estava bastante dependente do respeito pelas regras sociais, como eram as que categorizavam o pobre merecedor. Os comportamentos desviantes não só colocavam seus autores à mercê das medidas de controlo social, como comummente os excluía da fruição da caridade dos benfeitores, como era o caso dos presos. 0 respeito pelas normas não significava, no entanto, sua efetiva aceitação. 0 mais importante era demonstrar que se atuava em conformidade com elas. $E$ isso é bem visível em relação aos hospitais. Por exemplo, desde a reforma dos hospitais empreendida entre os finais do século XV e os primeiros anos do século XVI, que a Coroa portuguesa estabeleceu sua utilização como espaço de cura e não de hospedagem de pobres e peregrinos, ainda que estes pudessem possuir, nos hospitais, espaços de acolhimento temporário. Consultados os registos de entradas de vários hospitais urbanos ao longo do período moderno constata-se que a presença de mendigos entre os pacientes foi efetivamente reduzida. Porém, a análise ao vestuário que muitos doentes envergavam aquando do ingresso no hospital imediatamente remete para momentâneas mudanças de estatuto socioprofissional, que convertiam pedintes em "trabalhadores", como eram inscritos nos respectivos livros de admissão.

É, de resto, em relação aos hospitais, e não apenas em Portugal, que a referida ação coletiva, melhor, "ação social coletiva", ganha maior expressão e visibilidade. Isso porque já há provas bastantes demonstrando que muitos trabalhadores migrantes acediam gratuitamente aos hospitais quando eventualmente poderiam pagar o internamento, conforme determinavam os regulamentos. Não quer isso dizer que todos os trabalhadores hospitalizados tivessem recursos económicos. O que se pretende afirmar é que muitos deles o faziam com a conivência dos administradores dos hospitais, que, apesar de se queixarem do facto, permitiam que tal acontecesse. Não surpreende, pois, que os ritmos de entrada em vários hospitais urbanos acompanhassem as flutuações do trabalho sazonal, de acordo com as especificidades das economias locais, como era o caso da agricultura em Évora ou do sal em Setúbal, muitas vezes, nos períodos que mediavam entre o final de uma tarefa e o início de outra, por exemplo, entre o termo das colheitas dos cereais e o começo das vindimas. Como facilmente se depreende, o que estava em causa era menos facilitar o acesso dos trabalhadores aos cuidados médicos, sem o negar, como é óbvio, mas uma atuação, se não concertada pelo menos tácita, entre quem governava os hospitais e os centros urbanos (muitas vezes, os mesmos indivíduos), com evidentes benefícios ao nível da conservação da força de trabalho na comunidade e manutenção da ordem social. Alimentação e descanso - "o melhor remédio que o hospital pode dar", como repetem amiúde os médicos no século XVIII - eram as terapêuticas mais requeridas nessas circunstâncias. O que explica, por um lado, que as taxas de mortalidade hospitalar fossem, regra 
geral, bem mais reduzidas do que a historiografia do século XIX apregoou, e, por outro, que as médias de permanência se mantivessem relativamente baixas, ainda que um mesmo paciente pudesse recorrer ao hospital mais do que uma vez durante a mesma época laboral.

As explicações que defendem a "função social" dos hospitais modernos $^{22}$ em caso algum desvalorizam a fragilidade dos trabalhadores, estruturalmente no limiar da pobreza, à mercê de condições que não dominavam, nem negam a situação de miséria da maioria. Mas, nesses casos, como nos anteriores, o recurso ao hospital assumia a forma de pragmática estratégia de sobrevivência que acabava por ter efeitos similares em termos da economia e da sociedade que os acolhia, com a vantagem de os subtrair a pontuais situações de mendicidade ou mesmo de definitivo abaixamento de estatuto social.

Em suma, no contexto da ideologia mercantilista, e retomando o conceito de "ação coletiva", várias medidas foram tomadas pelas autoridades que acabaram por ter reflexos na saúde e no bem-estar das populações. A forma como os hospitais modernos foram administrados e o uso que os pobres deles faziam são prova disso. Certamente que se tem presente a distância que separa essas mesmas intervenções dos recentíssimos sistemas de saúde pública - organizados pelo Estado, que assume o controlo único do campo -, com o propósito de aumentar a população melhorando, por isso, as condições de vida e procurando diminuir os níveis de mortalidade. Porém, considerar as práticas passadas uma simples sucessão de factos, mais ou menos organizados, sem intencionalidade definida, é manifestamente redutor. Muitos dos fenómenos referidos foram objetivas manifestações do poder das autoridades envolvidas e tiveram resultados efetivos, entre outros aspectos, em termos de organização social.

\section{A intervenção organizadora da Coroa quinhentista}

No caso português, foi o poder central que, desde o primeiro momento, conduziu um conjunto de ações na área da caridade e saúde, iniciada sem qualquer estrutura organizativa, mas que ao longo de quinhentos se foi transformando num campo regulado e hierarquicamente dependente do monarca.

Tomem-se dois casos bem conhecidos: o dos hospitais e o das misericórdias. ${ }^{23}$ Estimulados pelas conclusões do Concílio de Viena de 1311, que

22 Na terminologia de Colin Jones e Michael Sonenscher, ainda que com significados mais alargados do que aquele que aqui defendo. Veja-se, desses autores: JONES, Colin and SONENSCHER, Michael. The social functions of the hospital in Eighteenth-century France: The case of the Hôtel-Dieu of Nîmes. French Historical Studies, v.13, n.2, p.172-214, Autumn 1983.

23 Para o desenvolvimento do processo dos hospitais, encontram-se alguns dados em ABREU, Laurinda. As crianças abandonadas no contexto da institucionalização das práticas de caridade e assistência, em Portugal, no século XVI. In: Actas do Seminário A Infância no Universo Assistencial no Norte da Península Ibérica (séculos XVI-XVIII), 
reconheciam os problemas em torno do governo das múltiplas instituições genericamente designadas por hospitais, os poderes públicos procuraram chamar a si, de forma ainda mais assertiva ao longo do século XV, o controlo daquelas fundações pias. Em Portugal, as informações que dão conta da pretensão de reforma dos hospitais por parte dos monarcas recuam, pelo menos, a 1432, momento a partir do qual é possível acompanhar as ações empreendidas junto ao papado com esse intento. Depois disso, impulsionadas por D. João II e por D. Manuel I, procedeu-se à concentração dos hospitais, à criação de hospitais centrais - de que é exemplo o Hospital de Todos os Santos, o modelo organizativo para o país -, e, especialmente, providenciaram-se as condições para a integração do património de capelas, hospitais e outras instituições caritativas nos Bens da Coroa. Foi essa incorporação, ocorrida sobretudo no reinado de D. Manuel I, que posteriormente permitiu aos monarcas transferir sem quaisquer constrangimentos um número considerável de hospitais para a administração das misericórdias. Quando esse movimento se intensificou, na década de 60 de quinhentos, por decisão régia ou solicitação das confrarias, estavam as misericórdias a viver um dos momentos mais relevantes do caminho que as conduziu a incontestável protagonismo na área da assistência e da saúde. Seis décadas volvidas sobre a fundação da Misericórdia de Lisboa (1498), eram já perto de duas centenas as misericórdias que se encontravam espalhadas pelo território nacional, colónias incluídas, detentoras de amplo leque de responsabilidades sociais - a que agora se juntavam a administração dos hospitais e, com ela, muitas vezes, o cuidado dos expostos -, património em crescimento e a confirmação da tutela régia, reconhecida pelo Concílio de Trento, tutela que as protegia do controlo da Igreja, mas que intervinha e fiscalizava, com especial destaque para o reinado de Filipe I, que foi também aquele que encerrou a obra iniciada por D. Manuel I. Refiro-me à provisão que o vice-rei, o cardeal-arquiduque Alberto, remeteu à Misericórdia de Lisboa em 30 de junho de 1593, e que depois seria aplicada às demais misericórdias.

Apesar de ainda não estar integralmente reconstituído o processo que envolveu essa provisão, tradicionalmente abordada como o documento que atribuía à Misericórdia de Lisboa o monopólio da realização dos préstitos fúnebres, ela tem, no meu entender, alcance bem mais vasto. A começar pelos intervenientes envolvidos: a Corte portuguesa, o papado, 122 confrarias de Lisboa e várias outras de Roma. Sentindo-se lesadas pelo breve de Inocêncio IX, de 20 de dezembro de 1591, que, a pedido de Filipe I, Ihes retirava direitos há muito consignados no tocante aos enterros,

p.31-49, 2008. Sobre as Misericórdias portuguesas a bibliografia é abundante e não seria possível apresentá-la aqui com o devido relevo. Remeto apenas às obras de Isabel dos Guimarães Sá, Maria Marta Lobo Araújo e Maria Antónia Lopes. 
as confrarias de Lisboa, com o apoio das de Roma, não só protestaram violenta e ruidosamente na capital portuguesa como recorreram ao papado suplicando a revogação do dito breve. Ainda o recurso corria, perturbado pela mudança de papa, em junho de 1593 o vice-rei confirmava o breve de Inocêncio IX e em dezembro ordenava que se agisse sobre os desordeiros e pusesse fim a controvérsia, que apelidava de "bastante incómoda para o reino e para o próprio rei". ${ }^{24}$

Que referia, afinal, a provisão de 30 de junho de 1593? Resumidamente, explicitava quais eram as áreas de intervenção social sob a responsabilidade da Misericórdia de Lisboa, ${ }^{25}$ determinava a proibição de qualquer outra confraria the fazer concorrência na prestação dos serviços assistenciais que oferecia ("derogando pera este effeito todos os estatutos e constituições apostólicas e tudo o mais que tiver necessidade de ser derogado") e reiterava a autoridade régia sobre a misericórdia. Na prática, tratava-se de quase declaração conjunta, da Coroa e do papado, em que se anunciava que a assistência era competência da misericórdia e que sobre a misericórdia prevalecia o rei. ${ }^{26}$ Nessa ordem interpretativa, a questão dos enterros deve ser reposicionada em função do essencial: a necessidade de garantir financiamento ao programa assistencial da Misericórdia de Lisboa. O que agora importa investigar é a celeridade com que a provisão de 1593 chegou a outras misericórdias e de quem terá partido a iniciativa de sua disseminação, se da Coroa, se das confrarias.

Esclareça-se, todavia, que a intervenção do poder central nas décadas finais do século XVI e nos primeiros anos do XVII não se limitou às misericórdias, estendendo-se também a um cada vez mais centralizado controlo das epidemias, ${ }^{27}$ ao apoio aos lavradores e camponeses, através da criação dos Celeiros do Trigo, à regulação das artes de curar e à formação académica de recursos de saúde. Nestes dois últimos casos, com resultados desiguais: enquanto a Coroa parece soçobrar perante os interesses antagónicos da Universidade de Coimbra e da Fisicatura-Mor - esta última, poder cuja dimensão ainda está por avaliar - ${ }^{28}$ conseguia impor, em 1568, novo tributo a

24 Lisboa. Biblioteca da Ajuda. (BA) Códice 47-VIII-2, fls.38-52.

25 Basicamente todas. Refere o documento que a Misericórdia socorria "as necessidades dos pobres, fazendo-lhes esmolas, vestindo nus e visitando enfermos com todas as cousas necessárias pêra seu remedio, casando orfãas, sustentando hum Hospital de incuraveis e aos encarcerados pobres e negociando-lhe seu livramento e soltura, mandando criar á sua custa meninos engeitados e orfãos, regatando cativos e acompanhando os que padecem por justiça, enterrando assi a elles como aos mais defuntos que nesta cidade fallecem, aos pobres dando-lhes mortalha quando a não tem e aos ricos por suas esmolas e pera este ministerio tem homens salariados e capellães". Cf. Portugaliae Monumenta Misericordiarum, 2006, p.57-58.

26 "Instituídas pêra cousas particulares e nellas somente entendem e se ocupão", as demais confrarias ficavam reduzidas às manifestações cultuais, enquanto a Misericórdia, "instituída ha mais de noventa annos, por ordem del Rey Dom Manoel de gloriosa memoria, e que nella se exercitão por seu principal instituto todas as obras de misericordia e charidade. Cf. Portugaliae Monumenta Misericordiarum, 2006, p.57-58.

27 Como observamos em ABREU, Laurinda. The city in times of plague: preventive and eradication measures against epidemic outbreaks in Évora between 1579 and 1637. Popolazione e Storia, n.1, Firenze, p.109-126, 2006.

28 ABREU, Laurinda. A organização e regulação das profissões médicas no Portugal moderno: entre as orientações da Coroa e os interesses privados. In: Arte médica e imagem do corpo: de Hipócrates ao final do século XVIII. 
mais de 70 municípios, obrigando-os a cofinanciar a formação de médicos e cirurgiões na Universidade de Coimbra. Em 1604, Filipe II aumentava a nova taxa em mais do dobro (de 715.000 réis para 1.600.000 réis anuais), justificando-o com a necessidade de igualmente formar 20 boticários, para além dos 30 médicos e cirurgiões anteriormente determinados. ${ }^{29}$

Como escrevemos em outro lugar, a incidência geográfica da contribuição "dos médicos", como ficou conhecida, foi a dos municípios de recente desenvolvimento, com predominância abaixo do Tejo, especialmente no interior alentejano, junto à fronteira. A capitação foi efetuada com base nos rendimentos concelhios, previamente avaliados pelos oficiais régios, o que explica a diferença dos valores tributados. Como também já analisámos, a implementação dessa nova estrutura, que ficou a cargo da Universidade de Coimbra, foi seguida de posterior movimento de colocação de médicos, cirurgiões e boticários, inicialmente nas localidades taxadas, ou pertencentes a sua jurisdição administrativa - como se as comunidades reclamassem a recompensa pelo investimento realizado -, alastrando-se progressivamente a outros espaços, até se difundir por todo o território nacional. Na troca de ofícios entre as câmaras municipais, que propunham à Coroa o nome de um profissional de saúde, solicitando seu recrutamento para assistir gratuitamente os pobres, e a autorização concedida pelo poder central, concordando com a remuneração proposta ou impondo outra em alternativa, intercepta-se elevado envolvimento do monarca, que abdica de parte de suas rendas, permitindo que a maioria dos salários fosse paga através das sisas - rendas pertencentes à Coroa -, em detrimento do recurso às fintas, que penalizavam sobremaneira os pobres, precisamente o públicoalvo desse novo benefício social. ${ }^{30}$

Esse exemplo, a par dos já mencionados, testemunha indiscutível padrão de exercício das prerrogativas da Coroa, que determinou uma muito particular evolução do quadro normativo e institucional formatador das políticas sociais ao longo de todo o século XVI. Situadas num contexto internacional, as decisões da monarquia portuguesa, as de D. Manuel I, mas também de seus sucessores, particularmente do cardeal-rei D. Henrique e de Filipe I, ganham espessura própria, revelando coerência e racionalidade que não podem ser subestimadas.

Michael Braddick, entre outros autores, tem insistido, a propósito da construção do estado moderno inglês, que o aumento da eficiência do governo durante o século XVII, nomeadamente em termos da arrecadação fiscal, não esteve apenas dependente do sistema administrativo, mas

Lisboa: Biblioteca Nacional, 2010, p.97-122

29 Esses boticários não estudavam na Universidade de Coimbra, que, entretanto, tutelava sua formação.

30 Quantificámos a participação das sisas entre $75 \%$ e $80 \%$, cerca de $15 \%$ a das rendas municipais, ficando o restante a cargo das fintas. Mas são valores provisórios, que necessitam de análise mais apurada. 
do contributo de outros fatores não institucionais. ${ }^{31}$ Algo semelhante foi propiciado em Portugal, nas décadas finais do século XVI, com o estabelecimento do novo serviço de apoio médico. Apesar da complexidade que envolveu, não exigiu qualquer inovação institucional nem aumentou a estrutura administrativa da Coroa que, pelo contrário, transferiu o ónus para a Universidade de Coimbra, impelida a cooperar com o poder central, já que à Academia competia a recolha do novo tributo (não era apresentado como tal, mas na prática tinha esse efeito), a seleção dos candidatos às bolsas devendo dar preferência, de acordo com as instruções régias, aos alunos provenientes dos municípios contribuintes - e acompanhamento próximo de seu percurso escolar, uma vez que o sistema previa a recompensa do mérito e a penalização do incumprimento das regras estabelecidas, como a da assiduidade - enorme encargo para a universidade, que a instituição terá capitalizado em benefício próprio, nomeadamente utilizando parte das verbas que recolhia na designada Arca dos Médicos e Boticários para pagar salários e prémios aos professores da Faculdade de Medicina em vez de os aplicar nas bolsas de estudo. A coincidência cronológica da implementação dessa estrutura com as novas prerrogativas conferidas à Faculdade de Medicina pelos estatutos reformados pela universidade em 1591, violentamente contestadas pelo físico-mor, que via perder parte de sua autoridade a favor dos médicos formados em Coimbra, pode não ter sido completamente alheia a esse processo.

Enfim, sem questionar os resultados práticos de tantas e tão variadas intervenções, o que pretendo reafirmar é que no último quartel do século $\mathrm{XVI}$ estava em funcionamento um conjunto considerável de instituições e serviços assistenciais que configurava uma densa rede de apoio formal. Pela mesma altura, também por iniciativa da Coroa, assistia-se a um reforço do envolvimento das elites locais na liderança do combate às pestes, e as misericórdias não só viam confirmada sua autoridade sobre a assistência às populações como tinham assegurado o domínio hegemónico sobre essa assistência (provisão de 30 de junho de 1593). O que há de comum em todas estas intervenções?

\section{Entre as orientações da Coroa e os interesses das elites locais}

A centralidade da monarquia enquanto organizadora das práticas de assistência formal em Portugal é inquestionável. Suas opções políticoideológicas marcaram o rumo a seguir, o que, por sua vez, Ihe facilitou a intervenção legal e normativa que em muito ultrapassou a esfera dos pobres e da pobreza, propiciando a regulação de múltiplos aspectos da

31 BRADDICK, Michael. The Early Modern English state and the question of differentiation, from 1550 to 1700. Comparative Studies in Society and History, v.38, n.1, p.92-111, jan. 1996. 
vida social, ${ }^{32}$ abrindo espaço ao cumprimento dessas regras, permitindoIhe fortalecer-se enquanto poder e aumentar sua autoridade. ${ }^{33}$ Mas a Coroa não esteve sozinha nesse processo; muito pelo contrário. No século $\mathrm{XVI}$ o governo central construiu parte de seu espaço político partilhando poder e recorrendo à negociação, como estipulava a cultura política, mas também garantindo a cooperação dos grupos dominantes no nível local. ${ }^{34}$ Nas questões assistenciais, D. Manuel I foi a figura determinante porque, para além da reforma dos hospitais, da fundação das misericórdias, ${ }^{35}$ do reforço das políticas sanitárias, da regulação das profissões médicas e da institucionalização da assistência aos expostos, a ele se deveu igualmente a criação das infraestruturas e dos procedimentos jurídicos (nos níveis judiciário, legislativo e administrativo) que acabariam por formar um sistema de normas nacionais, relativamente autónomo enquanto campo, aberto já à interação entre as diferentes partes que o compunham (recorde-se que foi esse monarca a iniciar a passagem dos hospitais para as misericórdias). No entanto, e para nos cingirmos apenas ao ponto central, quem estuda as misericórdias conhece bem suas dificuldades iniciais em termos de aceitação social, a desconfiança das instituições similares, que olhavam com suspeição para uma entidade que lhes chegava através da Coroa e mesmo a relutância das autoridades municipais, antecipando já possíveis encargos económicos associados às novas confrarias. Isso para concluir que, se o empenho de D. Manuel I foi fulcral para a constituição do sistema, ele dificilmente alcançaria a configuração que teve nos finais de quinhentos se seus sucessores não tivessem investido em sua consolidação, reforçando as estratégias manuelinas e apostando no papel catalisador das misericórdias $^{36}$ e na participação das elites locais como veículos de efetivação das propostas régias.

32 E nesse sentido compreende-se bem a intenção de D. Manuel I quando quis atribuir às Misericórdias competências para a concessão das licenças para mendigar.

33 É hoje mais aceite a ideia que venho defendendo há vários anos de que houve, desde cedo, uma intervenção do poder central nas Misericórdias. Intervenção legislativa, punindo os infratores, mas também arbitral, solicitada pelos próprios intervenientes. Há uma síntese sobre o assunto em ABREU, Laurinda. As Misericórdias portuguesas de Filipe I a D. João V. In: Portugaliae Monumenta Misericordiarum, 2002, p.47-77.

34 ABREU, Laurinda. Políticas de caridade e assistência na construção do Estado moderno: a especificidade portuguesa no contexto Ibérico. In: Actas do Congreso Internacional Las relaciones discretas entre las monarquias hispana y portuguesa: las casas de las reinas (siglos XV-XIX). Arte, música, espiritualidad y literatura. Universidad Autónoma de Madrid: Ed. Poligemo, 2008, v.ll, p.1451-1466.

35 Muito se tem escrito sobre a intervenção da rainha dona Leonor na fundação da Misericórdia de Lisboa. Em trabalho recente Isabel dos Guimarães Sá retoma o tema adiantando interessantes pistas de análise sobre o assunto. Veja: SÁ, Isabel dos Guimarães. A fundação das Misericórdias e a rainha dona Leonor (1458-1525): uma reavaliação. In: Jornadas de Estudo sobre as Misericórdias. Penafiel: Arquivo Municipal de Penafiel, 2009, p.15-33. Na perspectiva que desenvolvo é a vertente da ação política que mais valorizo e, nesse sentido, o inquestionável papel de D. Manuel I, conforme defendi em ABREU, Laurinda. Memórias da alma e do corpo. A Misericórdia de Setúbal na modernidade. Viseu: Palimage Editores, 1999, p.374.

36 Do que temos escrito sobre o assunto, destacamos a questão das indulgências papais, movimento comum às confrarias que, desde D. João III, entretanto, passou a privilegiar as Misericórdias (conforme o que observamos em ABREU, Laurinda. O século das Misericórdias. Cadernos do Noroeste, Série História 3, v.20 (1-2), p.467-484, 2003); a criação de condições específicas para a recepção dos legados pios perpétuos, no contexto do incentivo ao culto do purgatório oficializado no Concílio de Trento; a transferência dos hospitais para sua tutela e a facilitação 
A ligação das misericórdias às câmaras municipais foi, nesse sentido, uma ação política de elevadíssima eficácia. Começámos por o constatar no trabalho desenvolvido sobre a Misericórdia de Setúbal no período moderno. ${ }^{37}$ A continuação da investigação acabaria por expor o talento de alguns dos indivíduos anteriormente estudados revelado na criação de redes familiares e clientelares que Ihes permitiam circular entre a câmara e a misericórdia, ${ }^{38}$ evitando acumular funções nos dois locais, menos porque D. Manuel I assim o determinara, mas pela inutilidade de tal atitude: privilegiados com o mesmo tipo de benefícios em ambas as instituições, era-Ihes muito mais vantajoso ocupar a vereação ou a mesa da misericórdia em diferentes momentos, desde que conseguissem manter algum domínio sobre seus sucessores. ${ }^{39}$

Estudos para outras áreas geográficas haveriam de ampliar o leque de exemplos desse tipo de comportamento sem que, contudo, fosse dado relevo à circunstância que o proporcionava: pertencer a uma misericórdia era condição fundamental para forjar nova identidade social a quem provinha dos estratos inferiores, facilitando-lhe o reposicionamento na comunidade e o acesso ao circuito mencionado. Isso porque, ao estabelecer que as misericórdias deveriam ser compostas por igual número de irmãos de primeira e segunda condição (nobres e oficiais), a Coroa fazia depender do contexto local o grau da nobreza - circunstância que a breve prazo teria reflexos políticos, posto que contribuía para aumentar o número dos elegíveis para os cargos de governo municipal, juridicamente limitados aos nobres e "principais" das respectivas comunidades. Como exemplo, ao inscrever na lista dos nobres um ourives que não tinha sinais relevantes de elevada pertença social, as misericórdias estavam a provocar um "alargamento das fronteiras de elegibilidade", ${ }^{40}$ abrindo os caminhos do poder local a grupos que, sem essa forma de distinção, teriam maiores dificuldades em chegar aos cargos concelhios.

Como se sabe, o fenómeno não foi geral nem pode ser apresentado como regra absoluta. Como os estudiosos dessas áreas têm vindo a defender, os cenários sociais do Portugal de Antigo Regime eram muito diversos, e as análises têm de ser casuísticas. Nos grandes centros urbanos, com

da utilização dos bens alocados à celebração de missas na assistência hospitalar através dos Breves de Redução; e, naturalmente, a referida provisão de 30 de junho de 1593.

37 ABREU, Laurinda. A Santa Casa da Misericórdia de Setúbal de 1500 a 1755: aspectos de sociabilidade e poder Setúbal: Santa Casa da Misericórdia, 1990.

38 Sobre o investimento nas relações de parentesco, nomeadamente através da fabricação de genealogias e legitimação de novas identidades sociais pela criação de morgados e capelas, em Setúbal, veja-se ABREU, Laurinda. Memórias da alma e do corpo, p.172-191.

39 Não nos referimos, portanto, à complexa questão da cristalização oligárquica, sobre a qual existe abundante bibliografia, mas apenas às dinâmicas sociais abertas pela entrada numa Misericórdia.

40 Para usar a terminologia de Rui Santos quando se refere ao cargo de almotacé, em Mértola. Utilizamos do mesmo autor o conceito de elite: "numa perspectiva plural e flexível". SANTOS, Rui. Senhores da terra, senhores da vila: elites e poderes locais em Mértola no século XVIII. Análise Social, v.XXVIII (2), n.121, p.357 e 367, 1993. 
universos sociais dominados por poderosas oligarquias, fidalgas ou não, o efeito sociopolítico das misericórdias pouco se terá feito sentir. Como também não pode ser tomada como norma a apetência dos cargos camarários pelas elites instituídas. Nos pequenos e médios municípios abundam os exemplos de vereadores eleitos que sucessivamente recusam assumir os cargos porque não representavam qualquer mais-valia económica ou social, podendo, pelo contrário, onerá-los financeiramente.

Não são, no entanto, essas as situações que agora pretendemos destacar. Antes, casos como o de Setúbal, onde a produção salineira, em expansão desde meados do século XVI, alterou radicalmente as estruturas socioeconómicas, e os daquelas pequenas localidades de grande homogeneidade social, onde a existência de uma misericórdia funcionava como indicador de diferenciação, às vezes mesmo de criação de identidade local, como aconteceu em Penafiel no início do século XVI. ${ }^{41}$ Quando, em 1613, a Misericórdia do Porto tentou impedir a existência de uma confraria concorrente em suas proximidades, a argumentação usada ia no sentido mencionado: os proponentes da ideia apenas queriam apropriar-se do nome de "Misericórdia" para daí colherem os respectivos benefícios, eximiremse dos encargos concelhios "e de virem servir a esta cydade quando os há mister para bém comu". ${ }^{22}$ Propósitos que extravasam os do "amor ao próximo" são também os que se subentendem no pedido formulado pelos homens de Vila Nova de Anços, em 1633, para fundar uma misericórdia quando na mesma missiva reconheciam que o hospital e a albergaria existentes na vila satisfaziam as necessidades assistenciais da população. Ou ainda pelos de Castro Verde, em 1587, e pelos de Sortelha, em 1626, que informavam ter contraído pesados encargos económicos com o mesmo fim que os habitantes de Vila Nova de Anços. ${ }^{43}$

Sem que os possamos tomar como paradigmáticos, não deixa de ser relevante que a maioria dos exemplos conhecidos se reporte à passagem do século XVI para o XVII e às primeiras décadas deste, momentos em que, segundo alguns autores, ${ }^{44}$ se cristalizavam as oligarquias municipais, legitimadas pela legislação régia. ${ }^{45}$ Mesmo não desenvolvendo essa questão, que tem, como se sabe, muitas outras envolventes, certo é que, ao criar, a

41 Nuno Gonçalo Monteiro indica que mais de metade das câmaras existentes em Portugal no Antigo Regime tinha menos de 400 fogos. Cf. MONTEIRO, Nuno G. Elites locais e mobilidade social em Portugal nos finais do Antigo Regime. Análise Social, v.XXXII (141), p.335-368, 1997.

42 MIRANDA, Abílio. História da Misericórdia de Penafiel. Penafiel: [s.n.], 1987, p. 14

43 ABREU, Laurinda e PAIVA, José Pedro. Reforço da interferência régia e elitização. O governo dos Filipes - Introdução. In: Portugaliae Monumenta Misericordiarum, 2006, p.11-12.

44 Nomeadamente para Joaquim Romero Magalhães, um dos melhores conhecedores dessa problemática.

45 Na inventariação de Nuno Gonçalo Monteiro: "Foi a própria legislação da monarquia portuguesa a reconhecer o papel de liderança local que cabia às 'pessoas principais das terras' (1570), aos 'melhores dos lugares' (1603, Ordenações), aos 'melhores da terra' (1618), às 'pessoas da melhor nobreza' (1709), reservando-Ihes os 'principais ofícios da República' nas diversas povoações do reino". Cf. MONTEIRO, Nuno G. Elites locais e mobilidade social em Portugal nos finais do Antigo Regime, p.335-368. 
partir de uma instituição assistencial, condições para a formação de uma elite local com influência social, capacidade de acesso ao poder político e de organização de redes de poder, ${ }^{46}$ a Coroa não só facilitou a disseminação das misericórdias e do que elas significavam em termos de uniformização de práticas e procedimentos administrativos e normativos como potenciou as hipóteses de diálogo com as periferias. O que era por si só um facto importante foi-o ainda mais em tempos de monarquia ausente, como ocorreu durante o período filipino. Sabemos que as misericórdias não eram agentes do poder central, mas a possibilidade de se dirigirem diretamente à Coroa e o facto de à volta delas circular boa parte da vida comunitária, tornaramnas veículos privilegiados de comunicação entre o poder central e o país, permitindo àquela melhor conhecimento do reino, sem intermediação de outros corpos e sem custos financeiros.

Assumimos, assim, que a importância dessas ações não advém de seu sentido institucional, mas da quantidade - é importante ter presente que em 1640 existiam mais de 300 misericórdias no espaço português -e qualidade social dos mediadores. E mesmo concordando que o resultado final possa ter ficado aquém das expectativas da Coroa, o sistema assistencial português promovido no século XVI foi um dos mais uniformizados da Europa, tendo propiciado aos monarcas, repito, percepção mais aproximada da realidade do país e o fortalecimento de sua autoridade, inclusivamente por uma razão que continua a ser subestimada: a arbitragem de disputas surgidas no contexto da administração da assistência. Conflitos motivados pela partilha de heranças, incumprimento de legados pios, incorretas categorizações sociais, indevidas apropriações dos bens dos pobres, desrespeito pelas regulações impostas às misericórdias e aos hospitais, desprezo pela ordem das precedências e manifestações simbólicas, não pagamento de prestações sociais (para os presos e expostos), foram algumas das muitas situações em que as comunidades chamaram os tribunais centrais a intervir. Não esquecendo as frequentes lutas vividas no seio das misericórdias, protagonizadas por facções rivais, ágeis na delação e no recurso à mediação régia.

Resumindo, se a ação política foi propulsora de nova configuração das práticas e políticas de assistência e saúde, as interações sociais estabelecidas entre a Coroa e as comunidades, baseadas num esquema de ganhos mútuos, foram determinantes para o sucesso da iniciativa. Pese embora não tivessem sido planeadas como tal, as diferentes intervenções régias, e não apenas as que se desenvolveram em torno das misericórdias, acabariam por constituir um programa de ação em que todos os intervenientes tinham interesses diretos: o poder político, as elites locais e até os pobres, que

46 Cf. MANN, M. The sources of social power. In: A history of power from the beginning to A.D. 1760, Cambridge, 1986, p.6-7. 
passaram a dispor de distribuição organizada de recursos assistenciais. É certo que era distribuição discricionária, que privilegiava os residentes (à exceção dos hospitais) e abrangia universos quantitativamente circunscritos, mas pelo menos sabia-se como funcionava, o que aumentava as possibilidades de a conseguirem influenciar. ${ }^{47}$

\section{A razão de Estado e os novos paradigmas assistenciais: algumas mudanças propostas no século XVIII}

O investimento régio em novas políticas de assistência e saúde parece esgotar-se nas primeiras décadas de seiscentos. A partir de então e até à segunda metade do século XVIII, não se distinguem ações institucionais verdadeiramente consistentes em termos de inovação, procedimentos, estruturas ou formas de financiamento. Com muitas misericórdias a ameaçar ruína já no século XVII em resultado das enormes despesas com a assistência hospitalar e de desastrosas políticas creditícias - envolvendo maioritariamente os irmãos, as elites (mesmo as não representadas nas confrarias) e até a própria Coroa, que impôs a muitas misericórdias a aquisição de padrões de juros reais ${ }^{48}$-, o sistema foi-se esgotando, apesar de algumas medidas promulgadas por $\mathrm{D}$. Pedro II ou mesmo da reconstrução de vários hospitais durante o reinado de $\mathrm{D}$. João $\mathrm{V}$.

Foi com o novo ciclo político iniciado pelo governo de Sebastião José de Carvalho e Melo que as questões sociais, enunciadas sob os princípios do racionalismo iluminista e propósitos de progresso económico e social, ganharam renovado protagonismo. No momento em que várias sociedades europeias defendiam a saúde como bem social, também o governo português a assumia como responsabilidade pública, num sentido duplamente alargado - não exclusiva das situações epidémicas e mais preocupada com mecanismos de prevenção, com objetivos populacionistas. Pressupostos que ganharam corpo em várias medidas institucionais que visavam, simultaneamente, a maior fiscalização do campo e à reforma de alguns sectores. ${ }^{49}$

Apesar de ser mais conhecida a ação do secretário dos negócios do reino sobre as misericórdias, muito particularmente sobre a de Lisboa, colocada debaixo de cerrado controlo régio desde 1755, quando a Coroa

47 Fora desta análise fica a Igreja, vertente que desenvolvemos um pouco em ABREU, Laurinda. Defining the poor: between Crown policies and local actors (Évora, 16th-17th centuries). In BOURDELAIS, Patrice and CHIRCOP, John (eds.) Vulnerability, social inequality and health. Lisboa: Colibri/Cidehus/UE, 2010, p.77-91.

48 Cf. ABREU, Laurinda. Misericórdias: patrimonialização e controle régio (séculos XVI e XVII). Ler História, n.44, Lisboa, p.5-24, 2003.

49 Para um ponto de situação sobre as características do poder no período moderno, com revisão bibliográfica, consulte-se HESPANHA, A. M. e SUBTIL, J., Corporativismo e estado de policia como modelos de governo das sociedades euro-americanas do Antigo Regime. In: GOUVÊA, F. e FRAGOSO, J. (orgs.) O Brasil Colonial. Rio de Janeiro: Editora Civilização Brasileira (no prelo). 
suspendeu a realização de eleições anuais, ${ }^{50}$ foi sobre o Hospital de Todos os Santos que se exerceu, porventura, a dimensão mais relevante, e de efeitos imediatos, da atuação de Pombal na área da saúde. ${ }^{51}$ Ela demonstra, inclusive, a evolução do processo de decisão política, que num primeiro momento, na sequência do terramoto de 1755, apostou firmemente na recuperação do hospital, reorganizou seu funcionamento, as práticas curativas e pedagógicas (no nível da formação de cirurgiões e sangradores), e depois (1775) inflectiu o rumo e decidiu pela mudança de localização e até do nome do hospital, agora Hospital de S. José, simbolicamente alojado no Colégio de Santo Antão, que, tal como a igreja e o colégio de São Roque, ocupados pela Misericórdia desde 1768, tinham pertencido aos jesuítas. Verdadeiramente expressiva, nesse contexto, foi a decisão pombalina, inalterada por Dona Maria I, de proteger as misericórdias e os hospitais das leis de desamortização e das novas regras sucessórias e de vinculação da propriedade, bem como do subsídio militar da décima. Ao fazê-lo, a Coroa reconhecia, de facto, a importância social dessas instituições, mas admitia também a incapacidade de o Estado intervir economicamente nos hospitais, razão por que decidiu mantê-los, direta ou indiretamente, dependentes do financiamento da caridade, com todas as implicações que daí advinham.

Paralelamente, a Intendência-Geral da Polícia, criada por diploma de 25 de junho de 1760, recebia competências alargadas para o combate à criminalidade, que incluía vasto leque de medidas de fiscalização social e de ações tendentes à prevenção de comportamentos considerados desviantes. Seria já no governo de dona Maria I, com a nomeação de Pina Manique como intendente-geral da Polícia, que a instituição ganharia fôlego renovado, assumindo a liderança na implementação de novas políticas sociais e de saúde pública.

No contexto de um Estado polícia e conjugando os pressupostos teóricos da medical police, que ao tempo estavam a ser conceptualizados por Johann Peter Frank, ${ }^{52}$ com os princípios das ordenações da Polícia, de Nicolas de la Mare (1705-1738) - que Pina Manique frequentemente chama em sua defesa -, o novo intendente faz leitura muito ampla do objetivo de zelar pela "tranquilidade pública e segurança" da população, consignado no referido diploma de 25 de junho de 1760 e ampliado pela carta régia de 15 de janeiro de 1780 (que precedeu sua nomeação, a 18 de janeiro), que reforçou as jurisdições inerentes ao cargo. ${ }^{53} \mathrm{Em}$ termos práticos, e antecipando a formulação jurídica com que Pascoal de Melo e Freire estabeleceu as competências da Polícia em seu Novo Código de Direito

50 Situação que se manteria até 1812

51 Ao contrário do que aconteceu com a reforma do ensino da medicina determinada nos novos estatutos da Universidade de Coimbra, de 1772, com resultados muito lentos, como seria expectável.

52 FRANK, Johann Peter. System einer vollständigen medicinischen Polizey (obra editada entre 1779 e 1827).

53 Lisboa. Arquivos Nacionais da Torre do Tombo. (ANTT) Manuscritos da Livraria, n.1696. 
Público, de 1789, em que se encontram espelhadas muitas das atribuições que Pina Manique reclamava para a intendência-geral da Polícia, ${ }^{54} \mathrm{o}$ intendente tomou a administração das questões sanitárias, de saúde pública e de assistência, como outros tantos programas de controlo social e de civilidade da sociedade. ${ }^{55}$

Ainda que escasseiem os estudos sobre a ação social de Pina Manique, ${ }^{56}$ e não sendo possível desenvolver aqui todas as suas realizações nessa área, tomemos, de forma resumida, algumas de suas intervenções no âmbito da saúde pública e da proteção/reforma social, maioritariamente coordenadas a partir de uma instituição dependente da Intendência-Geral da Polícia: a Casa Pia de Lisboa, criada em 20 de maio de 1780, poucos meses depois de assumir o cargo de intendente.

No primeiro caso merece realce o vasto investimento na formação de profissionais de saúde qualificados, em medicina, cirurgia e obstetrícia, com o objetivo de os distribuir pelo país para que aplicassem e reproduzissem os ensinamentos recebidos ${ }^{57}$ - uma ação desenvolvida em vários contextos, em Portugal e no estrangeiro (Hospital de S. José, Coimbra (colégios e universidade), Londres, Edimburgo e Copenhagen) -, e a procura de maior envolvimento social dos médicos, chegando mesmo a idealizar programas de medicina pública gratuita para os pobres. Em conflito com a Universidade de Coimbra e seus professores de medicina, que acusa de pouco sensíveis às questões sociais, apela com regularidade ao saber especializado, obrigando os médicos a intervir em comissões de saúde pública quando necessita de pareceres informados que sustentem decisões políticas mais complexas. Quando em 1782 substituiu a Fisicatura-Mor pela Junta do Protomedicato, Pina Manique procurava acompanhar outros governos europeus: formar uma burocracia médica para atuar em nível nacional, com ampla jurisdição no campo da saúde e alargadas competências de intervenção. Uma instituição que fosse capaz de se impor aos interesses corporativos da Universidade de Coimbra e aos do físico-mor que, de acordo com os preços preestabelecidos, "fabricava", na terminologia da época,

54 Cf. O novo codigo do direito publico de Portugal, com as provas compil. pelo desembargador Paschoal José de Mello Freire dos Reis. $1^{\mathrm{a} e d}$. Coimbra: Imprensa da Universidade, 1844, p.139-143.

55 Excelente síntese sobre o conceito e práticas políticas associadas pode encontrar-se em HESPANHA, A. M. e SUBTIL, José. Corporativismo e Estado de Polícia como modelos de governo das sociedades euro-americanas do Antigo Regime.

56 Dos trabalhos mais recentes de cariz académico centrados em Pina Manique destacam-se o de BILÉU, M. M. C. Diogo Inácio de Pina Manique, intendente-geral da Polícia: inovações e persistências. Lisboa, 1995 (História, Dissertação de mestrado); e de FÉLIX, Patrícia. Diogo Inácio de Pina Manique, Intendant Général de la Police de la Cour et du Royaume de Portugal (1780-1805): pouvoir et actions face a la criminalite. Université de Marne La Vallée, 1998 (Histoire Moderne, maîtrise).

57 O recrutamento dos estudantes para o colégio criado em Coimbra tinha algumas semelhanças com a estrutura estabelecida em 1568, atrás referida. Num ofício dirigido a José Seabra da Silva, em 11 de dezembro de 1789, Pina Manique informa que enviara para o colégio "quarenta e seis estudantes de diversas terras das provincias deste reyno para aprenderem a faculdade de medecina e cyrurgia, e virem a servir de auxilio a algumas das mesmas terras, que se achão necessetados deste socorro". ANTT. Intendência-Geral da Polícia, maço 277, cx.370. 
grande variedade de profissionais de saúde, baseado no reconhecimento do saber empírico.

No segundo caso, o destaque coloca-se mais nas orientações ideológicas subjacentes às políticas sociais de Pina Manique do que nos resultados alcançados. É no planeamento e execução daquelas políticas que o intendente revela as contradições e complexidades de sua atuação enquanto responsável pela Intendência-Geral da Polícia. Mais empenhado na interdição dos comportamentos desviantes do que em prevenir a pobreza e eliminar as condições que a ela conduziam, Pina Manique desenvolveu uma política social compósita, que juntava práticas caritativas de pendor tradicionalista com ações de repressão com base no trabalho forçado e com o investimento na educação e formação profissional, estas de acordo com os ideais iluministas. Em cada um dos casos mencionados, o intendentegeral da Polícia defendia a institucionalização como meio privilegiado de atingir seus propósitos. Ainda que apregoasse que se limitava a seguir o exemplo de "todas as nações civilizadas", Pina Manique conhecia, por certo, as fortes críticas que ao tempo se faziam ouvir contra seus modelos, nomeadamente o dos hospitais gerais, na forma em que Luís XIV os divulgara, e o dos depósitos de mendicidade, fundados em França em 1767 e encerrados por Turgot em $1775 .^{58} \mathrm{Em}$ Portugal, desde 1780, uma constelação de instituições procurava assegurar, a partir da Casa Pia, funções educativas, formativas, repressoras e regeneradoras. Todas elas administradas sob os mesmos rigorosos preceitos disciplinares e morais que vigoravam tanto nos diferentes colégios de ensino como nos recolhimentos, casas de educação e casas de correção. Inaugurada com 13 órfãos e mendigos, em julho de 1780, em 1793 a Casa Pia de Lisboa tinha sob sua tutela 1.145 indivíduos espalhados pelas diferentes instituições.

Quando se analisam em conjunto as políticas sociais do Marquês de Pombal e do intendente-geral da Polícia, Pina Manique, não se pode deixar de reconhecer a existência de projetos ambiciosos e, em alguns casos, revolucionários. ${ }^{59}$ Mas, principalmente, a capacidade de terem recolocado o poder político no centro da decisão e organização da assistência (pelo menos, de parte dela) e da saúde pública. A intervenção de Sebastião de Carvalho e Melo no Hospital de Todos os Santos/S. José e na Misericórdia de Lisboa, ${ }^{60}$ as duas grandes instituições portuguesas de assistência e cuidados médicos, precisamente aquelas que $D$. Manuel I quis que fossem modelos a seguir pelo país, tem várias leituras. A questão que se coloca é a

58 Cf. CASTEL, R. Les métamorphoses de la question sociale. Paris: Librairie Arthème Fayard, 1995, p.150-151.

59 Vejam-se as medidas que então foram promulgadas em LOPES, Maria Antónia. A intervenção da Coroa nas instituições de protecção social de 1750 a 1820. Revista de Historia das Ideias, v.29, p.131-176, 2008.

60 Parece certa alguma animosidade entre Pina Manique e a Misericórdia de Lisboa não só a propósito do imbricado processo da criação da lotaria, que o intendente afirma ter sido o primeiro a solicitar para benefício da Casa Pia (ANTT. Intendência-Geral da Polícia, maço 588, caixa 980, doc.88), mas sobretudo porque era inevitável alguma concorrência entre ambas as instituições. 
de saber quais foram as verdadeiras repercussões dessas políticas no nível nacional, ou seja, para além da profunda renovação jurídica, do aumento do controlo régio, das novas políticas sociais, das múltiplas intenções de reforma, dos novos organismos, para além de tudo isto, repito, o que é que de facto mudou nas práticas assistenciais e no quotidiano das misericórdias e dos hospitais, tomados aqui como os pilares da assistência no Portugal de Antigo Regime? Concretamente, que resultados foram alcançados?

Ainda que, uma vez mais, a ausência de estudos não autorize a formulação de conclusões com carácter definitivo, são vários os indicadores que demonstram que essa influência foi reduzida, nula em muitos casos. Mesmo uma intervenção tão profunda e abrangente como a desenvolvida por Pina Manique não foi suficiente para estruturar um novo sistema. Revelam-no os inquéritos nacionais realizados no contexto da Junta de Saúde Pública, criada em 1813, bem como toda a documentação reunida aquando da elaboração do Projeto de Regulamento Geral de Saúde Pública, de 1821, entre muitos outros testemunhos que se poderiam referenciar.

A ambição expressa por Pina Manique de dotar todas as províncias do reino com casas pias idênticas à de Lisboa, ${ }^{61}$ é, porventura, um dos meIhores exemplos da dificuldade em transpor para o resto do país soluções experimentadas na capital. Ele próprio o terá sentido, não se devendo, na minha opinião, separar esse processo do diploma de 24 de maio de 1783, que determinava a criação de rodas em todas as vilas que não possuíssem estruturas de apoio às crianças abandonadas. Na impossibilidade de construir instituições da dimensão da Casa Pia de Lisboa, procuravam-se soluções mais acessíveis, na linha do que Pascoal de Melo Freire defendia em seu Código do Direito Público. ${ }^{62}$ Todavia, mesmo para esse processo, as resistências foram imensas e emanavam de todos os lados: das autoridades locais, das populações e até dos representantes do poder central. Apesar de ameaçar estes últimos com processos judiciais pelo incumprimento das ordens régias, como aconteceu, com o juiz de fora de Lamego, em 1803, apesar de, no ano anterior, ter ordenado aos ministros dos bairros de Lisboa que, no caso de não haver amas voluntárias, obrigassem as "mulheres de leite" que já tivessem exercido aquelas funções a sê-lo novamente, apesar das pedagógicas explicações que vai dando aos corregedores de comarca sobre como levar as crianças a mamar nas cabras na ausência do leite materno, apesar de tudo isto e de muitas outras ações, ${ }^{63}$ nem os índices

61 Desejo expresso em ofício de 4 de setembro de 1786 dirigido a Martinho de Melo e Castro, secretário de Estado dos Negócios Estangeiros. (ANTT. Intendência-Geral da Polícia, Contas para as Secretarias, Livro II, fls.261-264). Como se sabe, a Casa Pia fundada no Porto teve atribuições bem diferentes da de Lisboa, o mesmo acontecendo com a de Évora, criada em 1836.

62 O novo codigo do direito publico de Portugal, com as provas compil. pelo desembargador Paschoal José de Mello Freire dos Reis, p.142-143.

63 Informações retiradas de um núcleo documental que estamos a analisar constituído pelos "Avisos do intendentegeral da Policia da corte e do reino, Diogo Inácio de Pina Manique, aos provedores das comarcas do Norte, a 
de mortalidade dos expostos baixaram nem as rodas tiveram a implantação desejada.

Em síntese, apesar dos meios políticos e coercivos a seu dispor, os governantes do século XVIII fracassavam na criação de estruturas nacionais, ou seja, nas situações em que os monarcas de Quinhentos tinham tido sucesso. Como o explicar?

\section{Notas finais}

Apesar de rejeitar de forma categórica enveredar por uma análise das políticas sociais com base em quaisquer pressupostos de progressão linear de cariz teleológico, defendo que as dificuldades que o governo português encontrou nas décadas finais do século XVIII, quando procurou introduzir alterações substantivas nas políticas e nas práticas de assistência e de saúde pública, têm razões históricas e só se conseguem compreender numa perspectiva de longa duração - o que, apesar de tudo, não deixa de comportar alguma perplexidade, tendo em conta os recursos e a moldura institucional e ideológica dos governos de então.

Assumindo o risco de excessiva simplificação, e apesar da especificidade do enquadramento político da segunda metade de setecentos e das diferentes situações sociais, que configuravam novas problemáticas, a analogia entre esse período e o século XVI impõe-se por si própria. E isso por uma razão principal: porque são, ao longo do Antigo Regime, os dois momentos em que a saúde e o bem-estar da população parecem ter sido prioridades institucionais, motivando por parte dos poderes públicos, ainda que com distintas retóricas políticas, intervenções consistentes e sistemáticas em campos tão diversos como o da reestruturação dos hospitais e, em geral, organização dos recursos formais de assistência, formação das profissões sanitárias, reconfiguração do conceito de "pobre merecedor" e definição de regras para a atribuição de recursos, reforço das políticas contra a mendicidade e a vagabundagem, investimento nas crianças abandonadas e nos órfãos e aposta no trabalho com carácter preventivo e reformador. ${ }^{64}$ Do acima exposto releva a conclusão que o sistema cristalizou

respeito de providencias sobre engeitados". ACL. Série Vermelha, v.I, n.21.

64 Mas, se o movimento comporta originalidade nos meios usados e nas concepções políticas e ideológicas, assentes nas teorias utilitaristas de Bentham e nos princípios defendidos por Malthus segundo os quais a assistência devia ser reduzida ao mínimo necessário à subsistência (um princípio também defendido por D. Rodrigo de Sousa Coutinho em seu Discurso sobre a mendicidade), já a ideia do trabalho em troca da assistência tinha sido ensaiada em Évora, em 1589, no Hospício da Piedade, fundado por D. Teotónio de Bragança, sob as orientações de Miguel de Giginta. Um projeto com maior sucesso do que o seminário que, uns anos antes, a Câmara de Lisboa tinha apresentado à Coroa, onde se recolheriam os "moços vadios que vagueavam em Lisboa sem ordem nem ocupação de vida", a financiar pela edilidade, pelo rei, pela Igreja e pela Universidade de Coimbra. Cf. ABREU, Laurinda. Repressão e controlo da mendicidade no Portugal Moderno. In: Asistencia y caridad como estrategias de intervención social: iglesia, estado y comunidad (sécs. XV-XX). Bilbao: Servicio Editorial de la Universidad del País Vasco, 2007, p.95-119. 
em seiscentos, com notório enfraquecimento da intervenção da Coroa e fortalecimento da autoridade das elites locais sobre o campo. ${ }^{65}$ Defendo com isso, que não foi apenas a pressão do legado histórico que condicionou as mudanças experimentadas no século XVIII, mas, com ele conjugado, o poder dos grupos dominantes no nível local, que configuram resistências quase corporativas por parte das misericórdias, ainda que não houvesse qualquer traço de união horizontal entre elas. Sendo essa uma afirmação que comporta alguma polémica, necessitando de mais trabalho de arquivo para mais segura validação, vão nesse sentido os estudos exploratórios sobre o fluxo e a tipologia dos processos judiciais que, a propósito da assistência e da saúde, foram desencadeados pelas comunidades, recorrendo aos tribunais centrais.

De entre as muitas interpretações possíveis para a situação que ocorreu em Setecentos, as mais relevantes, à luz do quadro interpretativo que tenho vindo a propor, são as que assentam nas diferentes dimensões, interesses e atores que intervieram em todos os processos sociais direta ou indiretamente ligados às questões assistenciais e o modo como o fizeram, entre outros, a organização da vida nos centros urbanos, o trabalho e a mão de obra, a saúde e a doença. Pretendo com isso afirmar que, ao colocar esses assuntos sob o prisma da governamentalidade, os governos da segunda metade de setecentos, projetados sob novos paradigmas sociopolíticos, quiseram prescindir dos atores que poderiam, como acontecera anteriormente, contribuir para impor de forma hegemónica a visão da Coroa quanto ao modelo de assistência, e até de sociedade, que pretendia disseminar. Recorde-se que as políticas populacionistas tão caras aos novos governantes, em muitos casos, como o dos expostos, mas também dos cemitérios, das prisões e da própria mortalidade hospitalar, se ligavam às estruturas assistenciais existentes. Seria difícil alterar estruturalmente a situação se não se envolvessem as instituições que atuavam no terreno. O facto de, nem por uma vez, que saibamos, Pina Manique ter sugerido qualquer intervenção nas misericórdias nem solicitado seu apoio é um fator a ter em conta nesse contexto.

Mais do que o poder coercivo da administração central, foi a articulação entre os seus interesses e os das "pessoas principais" das diferentes comunidades que permitiu, em Quinhentos, construir um sistema novo, com uma dimensão verdadeiramente importante. O êxito da difusão da ideia das misericórdias, apenas para referir um único exemplo, é bem elucidativo nesse nível. No século XVIII, e como bem tem advertido José

65 O que, de certa forma, foi facilitado por um "sistema" em que as responsabilidades eram difusas e as leis se caracterizavam pela dispersão quer em termos de conteúdos, quer de definição do público-alvo. O que, aliás, era comum ao tempo. Veja-se, a propósito, a resenha que Steven King faz sobre o enquadramento legal inglês, em KING, Steven. Poverty and welfare in England 1700-1850. A regional perspective. Manchester: Manchester University Press, 2000, p.18-47 e 272-274. 
Subtil, eram outros os modos de governar, legitimados pelo poder que advinha do conhecimento propiciado pelas estatísticas, censos e relatórios sanitários. Mas por isso mesmo, ao aplicar as novas políticas sociais, o Estado prescindiu de interlocutores e ousou ameaçar judicialmente seus próprios representantes quando eles se escusavam a aplicar as diretrizes do centro, como ocorreu no referido caso das rodas dos expostos. Quer isso dizer, não só contribuiu para acentuar a conflitualidade interna, como fragilizou o diálogo com as elites locais, concorrendo para o colapso da cadeia de comunicação informal que ligava o governo ao país. Retome-se o caso das misericórdias: apesar de a Misericórdia de Lisboa estar a sofrer enorme pressão da Coroa desde 1755, como foi mencionado, no resto do país prevaleceriam as dinâmicas locais, amarradas a seus próprios interesses, lógicas e concepções, e, sobretudo, adversas à mudança quando ela não lhes era favorável. Além do mais, sabiam bem do poder que tinham e das dificuldades da Coroa em diminuir seu protagonismo no panorama da assistência nacional. Como proclamava Almeida Garrett no Parlamento, em 1854, as misericórdias eram "a mais benéfica das heranças que a velha monarquia deixou à nova", ${ }^{66}$ mas os governos liberais nada tinham sido capazes de fazer para as reformar.

Não pretendemos com isso relativizar o peso das decisões políticas como elemento estruturador dos mecanismos assistenciais depois de o termos considerado determinante no século XVI. O que afirmamos é que o impacto quanto à implementação, ou tentativa de implementação, das decisões da Coroa dependeu das formas que esses mesmos processos políticos assumiram. Obviamente, tendo em conta uma multiplicidade de variáveis não incluídas neste ensaio.

66 Discurso citado por FERREIRA, F. A. G. História da saude e dos serviços de saude em Portugal. Lisboa: Fundação Calouste Gulbenkian, 1990, p.258. 